\title{
Educacionalização como um processo de modernização em curso ${ }^{*}$
}

\author{
Marc Depaepe ${ }^{* * *}$ \\ Paul Smeyers ${ }^{* * * *}$
}

\begin{abstract}
Resumo
O presente artigo discute a noção de "educacionalização", entendida como a orientação global ou tendência de pensar a educação como ponto focal para abordar ou resolver os problemas sociais. A intenção deste trabalho é oferecer uma visão geral sobre o entendimento de educacionalização e apresentar outros trabalhos que o utilizam como principal lente teórica, propondo-se a ser uma leitura de referência sobre este conceito que vem sendo utilizado por diversos pesquisadores, principalmente na Europa e América do Norte. Em um primeiro momento, o artigo situa o conceito de educacionalização em diferentes momentos históricos, mostrando distintos entendimentos desde que foi cunhado na década de 1950 pelo sociólogo Janpeter Kob. Partindo dessas observações, o artigo discute o entendimento de educacionalização do social no cenário atual, mostrando uma progressiva reconfiguração dos processos escolarizados nesse sentido. Para finalizar, é apresentada uma revisão de alguns trabalhos articulados em torno deste conceito, oferecendo ao leitor a possibilidade de posterior aprofundamento no tema.
\end{abstract}

Palavras-chave: Educacionalização. Educação básica. Escola.

\footnotetext{
* Este artigo é uma versão revisada daquele publicado originalmente sob o título "Educationalization as an ongoing modernization process", na revista Educational Theory, v. 58, n. 4, em 2008.

** Professor na Katholieke Universiteit Leuven, Bélgica.

*** Professor de Filosofia da Educação da Ghent Universitye da Katholieke Universiteit Leuven, Bélgica.
} 
Em várias sociedades ocidentais, testemunhamos hoje uma tendência crescente para "educacionalizar"” problemas sociais. Como instituição, a escola, entre outras coisas, vem sendo considerada responsável por resolver as desigualdades sociais (relacionadas com classe, raça e gênero); por reduzir mortes no trânsito, obesidade, sexo na adolescência e destruição do meio ambiente; por melhorar a saúde pública, a produtividade econômica, a cidadania e até mesmo as performances em competições esportivas, como os jogos olímpicos. Imputar esses tipos de responsabilidades "sociais" às escolas é um processo que está em curso há um longo tempo e coincide com o papel da educação na formação do moderno Estado-nação. Esse fenômeno tem sido estudado mais na Europa do que na América do Norte e tem sido denominado Pädagogisierung - uma palavra alemã "guarda-chuva" de difícil tradução. Optamos, então, por utilizar "educacionalização" como o conceito geral para identificar a orientação global ou tendência de pensar a educação como ponto focal para abordar ou resolver os maiores problemas humanos. Neste artigo, pretendemos fazer uma discussão inicial do conceito e apresentar sugestões de leitura para aqueles que desejem prosseguir seus estudos nesse sentido.

Apesar do fato de que se tenha começado a considerar a "infância" como uma fase distinta de vida na Idade Média, foi no curso do século XVII e, ainda mais, nos séculos XVIII e XIX que houve claramente uma intensificação do foco dos adultos nas crianças e em sua educação. O ser criança tornou-se "educacionalmente" orientado - com certeza, pelo menos, no final do século XIX, com a decolagem do "sociedade escolarizada"'. A vida de uma criança era cada vez mais vista e estruturada a partir da perspectiva de ser um "aluno"'. Michael-Sebastian Honig (1996) concebeu esta "educacionalização", no final do século XX, como a institucionalização da infância enquanto subsistema social, identificando, assim, uma gama independente de funções que preparavam a nova geração para a participação na cultura, na política e na economia. É fundamental destacar que o sucesso da escolarização assentou-se em um padrão assimétrico de relação educacional em que, graças à autoridade do professor, a moldagem dos alunos na direção de um comportamento socialmente desejável tornou-se possível. Como um agente de construção das nações modernas, desde o Iluminismo, o projeto de escolarização manifestou-se como uma versão secularizada da cristianização (BUGNARD, 2006). O professor encarnou a compulsão pastoral da educação. Sendo fonte de autoridade, sabedoria, bom comportamento e moral, o professor atuou como um piloto a quem os alunos estavam submetidos na sala de aula. O professor sabia o caminho que tinha de ser seguido e as melhores técnicas a serem aplicadas. A principal preocupação era a de "salvar" a criança, oferecer-lhe 
ajuda para que não fosse prejudicada. Este aumento da atenção sobre a esfera pedagógica também foi concebido para alcançar a elevação moral do povo (DEPAEPE et al., 2009). A educacionalização estava associada à moralização. Mais pedagogia, portanto, não resulta necessariamente em maior autonomia para a criança, mas pode, inversamente, resultar na ampliação da sua dependência.

Este é, ainda, o caso no século XX, no decurso do qual a coerção moral e ideológica do indivíduo foi substituída por uma justificativa do ponto de vista do desenvolvimento de si. Em ambos os casos, na mitificada ideologia educacional progressista americana e na Reformpädagogik europeia, sobre a qual inúmeros crentes depositavam confiança, a educacionalização ganhou a aparência de “orientada para a criança". A maior ênfase foi colocada em "autorrealização" e "autodesenvolvimento". Como consequência da crescente secularização e do estilo de vida livre dos anos pós-guerra, esses termos foram gradualmente retirados das exigências obrigatórias dos quadros normativos em que tinham surgido. Intervenções pedagógicas foram legitimadas em referência à noção de que não iriam nem fazer mal aos indivíduos, nem lhes causar frustração - e isso não aconteceu sem tendências infantilizantes. Com estas mudanças, ofensas e elementos brutais de violência física foram substituídos (pelo menos ao nível da retórica da correção pedagógica) pelo sorriso doce, o qual emana da esfera forçada de harmonia e prazer, que, se necessário, é imposta sobre a realidade educacional através do uso de ameaças psicológicas e truques. Nessa sociedade educacionalizada, educadores continuaram a isolar crianças e adolescentes (como diferentes dos adultos) na ilha protegida de uma instituição chamada "escola". E, nesta instituição, ainda se professava o axioma que relações com crianças livres de problemas são possíveis quando se aplicam os princípios "certos", ou seja, "cientificamente justificados" (DEPAEPE, 1998).

É mais ou menos neste contexto histórico que o conceito de “educacionalização" surgiu na Alemanha. O termo foi cunhado pelo sociólogo Janpeter Kob durante o final da década de 1950 (HÖHNE, 2004). Kob queria indicar, a partir de uma perspectiva educacional, a tendência que surgiu em praticamente todas as instituições de uma sociedade que se modernizava. O estado de bem-estar ocidental revelou-se principalmente como "educacional". Essa característica estava relacionada a uma fome de poder corporativista por parte de grupos profissionais, o que foi criticado por Helmut Schelsky (1961) e outros. Grupos profissionais devem ter lutado, entre outras coisas, pela expansão do poder educacional, a fim de alcançar melhores perspectivas de emprego. Em contraste com conceitos similares, como "industrialização" e "burocratização", o conceito de educacionalização, inicialmente, teve dificuldade em ser aceito. Na historiografia educacional alemã, só lhe foi concedida legitimidade nos anos 1980 (DEPAEPE et al., 2009). 
Nesse período, foi crucial o trabalho do educador alemão Ulrich Herrmann (1986), que desenvolveu uma concepção quase "programática" deste conceito em seu padrão de trabalho sobre a história social da criança. Para Herrmann, o processo de educacionalização teve tanto aspectos quantitativos quanto qualitativos. Assim, a ideia de expansão, em relação à ação educativa, concerne não só a um aumento do número de órgãos governamentais de assistência à infância e educacionais e a uma maior gama de processos educativos e pedagógicos, como também ao papel cada vez mais central da educação na sociedade. Como já indicado, este processo apresentava-se, principalmente, como uma mudança no repertório comportamental dos pais ou do professor. Ou, em outras palavras, do educador: a compulsão física (que também foi acompanhada por pressão psicológica) teve de dar lugar a um "tratamento" mais psicológico da criança. Elementos brutais de violência física foram "profissionalmente" convertidos em uma intervenção educacional "desencarnada", que tende a intensificar a manipulação emocional.

O que é essencial na análise de Herrmann e de outros, no entanto, é a ligação com a ideia de profissionalismo. Esta tendência de educacionalização foi entendida, principalmente, como resultado de um aumento da especialização que surgiu graças à cientificação (acompanhada pela academicização) da pedagogia e das ciências da educação. E, na medida em que o aumento do profissionalismo também forneceu estratégias para a solução de problemas que, inicialmente, não pertenciam ao campo profissional de educadores, psicólogos e outros semelhantes, isto, naturalmente, também rendeu avanços territoriais para os grupos profissionais envolvidos. Neste sentido, o fenômeno da educacionalização pouco diferia, por exemplo, daquele da medicalização, em que mecanismos análogos de anexação e de colonização levaram a ganho de status. Um bom exemplo de tal anexação territorial por meio de "educacionalização" é, em nossa opinião, a "punição educativa" (leia-se: treinamento) que estava prevista na Holanda, em meados dos anos 1990, por ordem do Ministério da Justiça, para os pais de alunos cabuladores persistentes. Ao se fornecer intervenções educativas específicas para lidar com "novos" grupos e categorias de casos problemáticos, novos mercados foram abertos no campo profissional. Do ponto de vista do mercado, a evolução da educação especial para a educação inclusiva, por exemplo, pode ser vista sob uma nova luz. Tanto a inicial "exclusão" de alunos "anormais" (desde o final do século XIX) quanto a "inclusão" dos alunos problemáticos no ensino regular (no final do século XX e início do século XXI) são, em última análise, expressões de um mesmo fenômeno. Especialistas em educação primeiro exigiram a segregação de casos problemáticos, que deveriam estar a cargo de profissionais em instituições especiais. Este mercado "excludente" ficou 
saturado e iniciou-se um movimento em direção à integração. Isso coincidiu com a detecção de problemas comportamentais e de aprendizagem cada-vez-mais-específicos entre as crianças "normais" (ou "comuns") (tais como o Transtorno do Déficit de Atenção com Hiperatividade - TDAH, superdotadação, dislexia, e assim por diante).

Embora educacionalização, como um conceito "neutro", pretenda descrever esses fenômenos como um subprocesso da "modernização" da sociedade, o conteúdo das orientações desse processo (e as contradições internas ou paradoxos que o acompanham) conferiram-lhe conotações negativas. Como educacionalização poderia ser facilmente entendida como uma oposição a autonomia, libertação e independência - devido ao aumento de dependência, tutela, paternagem, maternagem, infantilização, mimos e assim por diante -, neste sentido, também, parece-se bastante com "medicalização". Um maior estoque no mercado médico não conduz, necessariamente, a uma sociedade mais saudável, mas pode aumentar significativamente o consumo e dependência dos "cuidados de saúde".

A ironia que acompanha o conceito de educacionalização tem atraído a atenção de mais de um autor. Vamos dar dois exemplos: o primeiro tomado da década de 1980, o segundo, de duas décadas depois.

Para o filósofo francês Jacques Rancière (1987, p. 221-222), o paradoxo fundamental da educacionalização começou com as ideias do Iluminismo, que foram propagadas pelos republicanos:

Bastaria aprender a ser homens iguais em uma sociedade desigual. Isso é o que significa emancipar-se. Mas esta coisa tão simples é a mais difícil de compreender, sobretudo desde que a nova explicação, o progresso, misturou inextricavelmente um com o outro, a igualdade e seu oposto. A tarefa para a qual habilidades e corações republicanos dedicaram-se foi a de fazer uma sociedade igualitária de homens desiguais, para reduzir a desigualdade para sempre. Mas aqueles que assumiram esta missão tinham apenas uma maneira de alcançá-la: a educacionalização integral da sociedade, isto é, a infantilização geral dos indivíduos que a compõem. Mais tarde, isso seria chamado de educação continuada, ou seja, a coextensividade da instituição explicativa e da sociedade. A sociedade daqueles que são inferiores/superiores será igual; ela terá reduzido suas desigualdades quando estiver totalmente transformada em uma sociedade de explicadores explicados.

Aparentemente, não pode haver emancipação sem infantilização e educacionalização.

Por outro lado - assim ensina uma coleção austríaca editada por Erich Ribolits e Johannes Zuber (2004) - educacionalização não leva à emancipação, mas à sujeição do espírito. Em vez de adaptar a sociedade para as pessoas, o processo de educacionalização (que constitui a resposta lógica à globalização e à modernização em nosso próprio tempo) leva à adaptação das pessoas à sociedade neoconservadora. O resultado é, portanto, a domesticação do pensamento e não a emancipação. 
Educacionalização, como o título da coleção de Ribolits Zuber expressa ${ }^{1}$, é a arte de fazer as pessoas cada vez mais "estúpidas" por meio da aprendizagem. Aqui, a noção frequentemente elogiada de “educação permanente” vem de novo à mente. De acordo com Ribolits e Zuber (2004), o fenômeno da educacionalização difundiu-se de forma constante graças ao contexto neoconservador ${ }^{2}$. Nesse contexto, o eu tem que provar constantemente seu valor de mercado, por meio de "empregabilidade", "adaptabilidade", "flexibilidade", “educabilidade” e assim por diante. Isso levou não só à erosão da ideia de educação permanente - toda a criatividade é subordinada ao discurso regulador da economia e tecnologia do conhecimento -, como também da própria aprendizagem, que é reduzida a uma krisentaugliche Veränderungsroutine $e^{3}$ (ORTHEY, 2004). Os bobos da corte pós-modernos conhecem apenas a ideologia da ilusão tola do trabalho para o qual eles estão sendo preparados por meio de uma mudança universal e da "solução" modelo de flexibilidade. No momento, o lema para a aprendizagem pode ser resumido como a preparação para a autoadaptação à mudança (GRUBER, 2004), refletindo um certo tipo de personalidade que floresce na nova economia e, com referência ao conceito de Bauman (2000), prospera na "modernidade líquida" - uma personalidade orientada para si mesma, sem olhar para trás, pensando apenas no curto prazo (SENNETT, 2006).

Partindo dessas observações sobre a existência de processos de larga escala na história da educação, nós incorporamos o conceito de educacionalização em nossa própria pesquisa. Durante a última década, por exemplo, tentamos refinar, a partir dessa perspectiva, as iniciativas americanas para identificar a virtualmente universal "gramática da escolarização" (TYACK; CUBAN, 1995).

De fato, como resultado de uma visão por demais comportamental do que realmente acontece no local de trabalho, estas iniciativas levam em conta apenas o comportamento pedagógico observável, sem prestar muita atenção no contexto educacional, e muito menos no cultural, ao qual o comportamento educacional é incorporado. Por isso, desenvolvemos o conceito de "gramática da escolarização", no nosso estudo de caso do ensino primário belga, como uma estrutura pedagógica que tem de ser relacionada, pelo menos, com o contexto social moralizador da "educacionalização", entendida como um subprocesso de modernização total da sociedade (DEPAEPE et al., 2000). O arquétipo desta gramática pode ser facilmente encontrado em museus de "educação" no mundo todo. Que esses museus de educação respirem o mesmo espírito em quase toda parte mostra o quão universal é o "texto" da gramática escolar - mesmo que o "contexto" social e cultural ao longo destes vários períodos seja caracterizado por importantes distinções. Da mesma forma, isso prova o quão profundamente a gramática da escola está entrelaçada com os processos de modernização, globalização 
e educacionalização. Em várias línguas e no contexto de diferentes culturas, o mesmo "regime educacional" estabeleceu-se em quase todo o mundo "civilizado": um complexo semelhante de ações com o objetivo de formar estudantes (para mais tarde), disciplinando-os. Isto é evidenciado não só pelo comportamento educacional e o modo como as crianças são tratadas pedagogicamente, mas também pelos determinantes da própria cultura escolar. Cultura escolar pode ser definida, na tradição da pesquisa histórica francesa, como todo o conjunto de normas que determina os rumos da educação, a fim de obter o conhecimento do conteúdo e o comportamento social dos alunos desejáveis (NÓVOA, 2001). No entanto, esta "arqueologia" do ensino e dos rituais associados com a vida escolar não pode ser vista isoladamente do significado "educacional" de conduzir uma escola. Do nosso ponto de vista, é apenas com base na "semântica" da teoria educacional por trás das práticas pedagógicas que o conceito americano de "gramática da escolarização" pode ser totalmente interpretado. Uma "gramática da educacionalização" (ou, mesmo, educacionalizadora) é, portanto, em nosso entendimento, um complemento inevitável para a "gramática da escolarização". Além disso, a utilização deste conceito pode ser um antídoto contra a baixa consciência teórica da história da educação. Quando Heinz-Elmar Tenorth (1996) avaliou o estado da arte da historiografia educacional, ele defendeu explicitamente a necessidade de um aumento na construção teórica interna. Existia conhecimento profissional suficiente e não havia falta de publicações acadêmicas no campo da história da educação, mas essa enxurrada de produção de conhecimento não corresponde, necessariamente, a um avanço na compreensão em um nível mais alto de abstração. Muitos estudos foram restritos a uma colagem de fatos empíricos dentro da própria região cultural do autor, sem contribuir muito para a construção de teorias comparativas, para não falar em globalizantes, no que diz respeito ao fenômeno da escola e da educação aí oferecida ${ }^{4}$. Apesar da preferência paradigmática prevalecente no campo por modelos explicativos sócio-históricos e cultural-históricos, pode-se notar que a história dos pesquisadores em educação, uma vez que deixem a familiaridade das fontes dos materiais, voltam-se, principalmente, para conceitos-chave, estruturas narrativas e teoremas que foram desenvolvidas fora do contexto específico do passado educacional. A "grande teoria" foucaultiana é, por exemplo, um modelo básico dentro da "nova história cultural da educação" que tem sido desenvolvida nos Estados Unidos e em outros lugares ${ }^{5}$. Essas teorias fragmentárias importadas da filosofia, das ciências sociais e da historiografia geral podem bem orientar a estratégia disciplinar que se expressa por meio da educação, bem como a resistência que podem gerar na multidão a ser disciplinada, mas em nenhum caso fornecem - nem mesmo depois da chamada "virada linguística" nesta (sub)disciplina - uma leitura estrutural do "texto" que os próprios processos de educação e de escolarização produzem. 
Em um esforço para fazer avançar tal construção teórica desde o interior do campo, decidimos organizar em 2007 uma conferência sobre a educacionalização de problemas sociais (SMEYERS; DEPAEPE, 2009). Esta ocorreu no âmbito dos seminários interdisciplinares anuais do grupo de pesquisa "Filosofia e história da disciplina de educação: avaliação e evolução dos critérios para a pesquisa educacional” (criado em 1999 pela Fundação de Pesquisa Flandres, Bélgica). Um dos objetivos desta conferência foi o de expandir o "conceito guarda-chuva" historicamente gerado de “educacionalização” por meio de uma articulação entre teoria educacional e filosofia da educação.

A conferência contou com a participação de dezenas de colegas, ligados a diversas universidades espalhadas pelo mundo, sendo três delas localizadas na Bélgica ${ }^{6}$. Como resultado das discussões, cinco livros, organizados por Paul Smeyers e Marc Depaepe, foram publicados até agora: Além do empirismo: em critérios de pesquisas educacionais (SMEYERS; DEPAEPE, 2003), Pesquisa educacional: por que “o que funciona” não funciona (SMEYERS; DEPAEPE, 2006), Pesquisa educacional: redes e tecnologias (SMEYERS; DEPAEPE, 2007), Pesquisa educacional: a educacionalização de problemas sociais (SMEYERS; DEPAEPE, 2009) e Provas, argumentos e outros raciocínios: a linguagem da educação (SMEYERS; DEPAEPE, 2010). Essas publicações contêm artigos produzidos pelos diversos pesquisadores, apresentando análises e pontos de vista originais acerca da pesquisa educacional. Além destes livros, cinco artigos, também originários desta conferência, foram reunidos em um dossiê publicado pela revista Educational Theory, em 2008. Tendo em vista que o presente trabalho propõe-se a ser uma leitura de referência sobre o conceito de educacionalização, porém levando em conta as limitações em relação a sua extensão, na sequência comentaremos brevemente os artigos desse dossiê, que representam contribuiçõos importantes e de destaque para este campo, trazendo problematizações variadas que ajudam a produzir novos modos de compreender este tema.

Em seu ensaio "A Governamentalização da Aprendizagem e a montagem de um aparelho de aprendizagem”, Maarten Simons e Jan Masschelein (2008) ressignificam os conceitos de “educacionalização" e de "gramática da escolarização" à luz da enorme importância concedida ao "aprender" hoje. Dada a importância atual da aprendizagem, eles colocam em dúvida se os conceitos de "educacionalização" e de "gramática da escolarização", junto com perspectivas histórico-analíticas, ainda são úteis para compreender o presente da escola/educação. Eles sugerem tomar "aparelho de aprendizagem" como um conceito alternativo para abordar estas questões e como um ponto de partida para uma análise que incida sobre a "gramática da aprendizagem”. Para desenvolver esta análise, eles 
utilizam-se de Michel Foucault, em particular, de sua análise da governamentalidade. A aprendizagem tornou-se uma questão de governo e autogoverno, que eles descrevem como a "governamentalização do aprendizado". A fim de descrever a governamentalização da aprendizagem e da montagem de um "aparelho de aprendizagem", hoje, eles indicam como o conceito de aprendizagem, desligado da educação e do ensino, tem sido usado para se referir a um tipo de capital, a algo pelo qual os próprios alunos são responsáveis, a algo que pode e deve ser gerido e a algo que tem de ser empregável. O ensaio mostra como esses discursos são, hoje em dia, combinados e desempenham um papel crucial em um neoliberalismo avançado que visa promover o empreendedorismo. Simons e Masschelein explicam que o empreendedorismo implica uma ética de adaptação com base em automobilização através da aprendizagem, e que o neoliberalismo se baseia em uma espécie de aparelho de aprendizagem para garantir a adaptação de cada um e de todos.

Naomi Hodgson (2008) revê a sugestão de Marc Depaepe (1998) de que a tese de normalização de Foucault é inadequada para o estudo da educacionalização. Ela toma, como um exemplo de educacionalização de problemas sociais, a introdução de educação para a cidadania na Inglaterra e em outros lugares, o que é muitas vezes visto como uma resposta a problemas sociais contemporâneos, tais como a falta de participação democrática, comportamento antissocial, imigração e globalização. Ela também aborda os resultados das pesquisas educacionais sobre a recente introdução da educação para a cidadania, na Inglaterra, o que é ilustrado por uma revisão de pesquisas, políticas e práticas recentes, financiada pela Associação de Pesquisa Educacional Britânica. Essa revisão destaca que os estudos sobre sociologia política da educação são realizados de acordo com os conceitos de sua disciplina mãe, a sociologia, mas que eles não têm comprometimento teórico crítico com esses conceitos. Em vez disso, eles são operacionalizados a serviço de soluções para as políticas educacionais. Esse trabalho é realizado, portanto, na linguagem da política que ele procura avaliar de forma crítica. Três discursos dominantes são identificados em uma leitura da revisão: o discurso acadêmico da sociologia política da educação, o discurso político contemporâneo e o discurso da educação inclusiva - o que chama a atenção para o tratamento da educação para a cidadania e sua relação com a política como uma instância de educacionalização. À luz da natureza da articulação identificada entre o estudo da educação para a cidadania e sua política educacional, o conceito de normalização de Foucault é, então, considerado em termos de demanda sobre o sujeito contemporâneo no sentido orientar-se por uma relação voltada para a aprendizagem, que é informada pela necessidade de competitividade no contexto europeu e global. No final, Hodgson argumenta que a linguagem e a retórica da sociologia política da educação implicam tal pesquisa no próprio processo de educacionalização. 
Bert Lambeir e Stefan Ramaekers (2008) partem da observação de que os teóricos, quando se discute a "educacionalização de problemas sociais", muitas vezes referem-se a isso em termos condescendentes. Dada sua confiança nas perspectivas pós-modernas e pós-estruturalistas, a educacionalização de problemas sociais é facilmente percebida como um conjunto de intervenções questionáveis, por parte dos governos, na prática educacional. A partir dessa perspectiva, as escolas são, antes de tudo, sujeitas a mecanismos modernos e sistemas de controle foucaultianos, e os governos democráticos parecem ser ligeiramente totalitários ao educacionalizar ou sobre-escolarizar a realidade social. Lambeir e Ramaekers (2008) perguntam em que medida é possível conceber qualquer problema social sem uma compreensão educacional - ou, mais incisivamente, em que medida são concebíveis problemas sociais não integrados em alguma forma de educacionalização. Eles examinam três críticas populares: em primeiro lugar, o argumento de que a educacionalização é baseada em uma ideia moderna da educação; em segundo lugar, que a educacionalização é uma maneira de os governos eximirem-se de suas responsabilidades políticas; e, em terceiro lugar, que educacionalização é o mesmo que (ou é sintomática de) processos de governamentalidade. Eles ilustram a sua posição por meio de um exame das preocupações sobre iniciativas em educação em saúde e vinculam este exemplo específico à sua análise das críticas que acabamos de mencionar. Assim, eles investigam em que sentido a educação nunca pode ser completamente liberta da educacionalização de questões sociais. Eles argumentam que há algo a ser dito sobre a ideia de que a educacionalização de problemas sociais é característica de qualquer governo (razoavelmente) normal e funcional. Um governo que faça uso de estruturas e instituições sociais existentes, a fim de lidar com os problemas sociais, eles concluem, não deve ser, necessariamente, considerado como se eximindo de sua responsabilidade, mas, sim, como tentando intervir de modos particulares (e, assim, assumindo sua responsabilidade).

David Labaree (2008) explora a natureza da educacionalização no contexto norte-americano. A justificativa, ele argumenta, é esta: não podemos entender o crescimento da educacionalização nos Estados Unidos - em face da contínua falha da educação em corrigir os problemas sociais que lhe são atribuídos - a não ser que se considere algumas das necessidades sociais que esse processo expressa e as funções sociais a que este processo serve (para além de corrigir o problema). Alinhado com esse objetivo, ele começa por examinar as maneiras pelas quais o processo de educacionalização dos problemas sociais está profundamente fundamentado em crenças norte-americanas, processos sociais, tensões políticas e organizacionais e limitações estruturais. Em seguida, ele examina as raízes do fracasso da educação no papel de agente de reforma social e termina com uma análise de por que 
continuamos a perseguir a educacionalização mesmo em face de sua ineficácia. Labaree (2008) argumenta que a "gramática da escolarização" não é apenas uma estrutura que molda a educação e preserva sua forma ao longo do tempo; é também um padrão discursivo e comportamental que molda o modo como a sociedade funciona. Este processo tem seus usos sociais, que ajudam a reforçar e preservar a expansão da educação, uma vez que esteja em movimento. A educacionalização da sociedade integra-a em torno de um conjunto de experiências comuns, processos e linguagens curriculares. Ela estabiliza e legitima, primeiramente, uma estrutura social de desigualdade que, caso contrário, poderia conduzir-nos a um conflito aberto, e, além disso, um governo, fornecendo uma instituição para a qual podem ser atribuídos os difíceis problemas sociais e que pode ser responsabilizada quando esses problemas não são resolvidos. Acima de tudo, ela nos dá um mecanismo para expressar uma séria preocupação com os problemas sociais sem fazer nada eficaz para resolver esses problemas. Nesse sentido, então, a capacidade das escolas para formalizar uma substância - de transformar qualquer coisa importante em um conteúdo, um programa ou uma referência escolar - está no cerne do seu sucesso em educacionalizar a sociedade. Labaree (2008) conclui que, embora a educação não se dê conta de alguns de seus objetivos declarados, ela cria um conjunto de formas educacionais - estruturas, processos, cursos e linguagens - que desempenham um papel útil para a sociedade. Assim, ao educacionalizar problemas sociais, nós podemos não fazer muito para resolver os problemas, mas estamos fazendo um grande negócio para as próprias escolas.

Finalmente, David Bridges (2008) estabelece, juntamente com a análise da educacionalização, duas considerações. Primeiro, ele aponta para a forma como as instituições educacionais compactuam e, até mesmo, exploram a tendência educacionalizante do governo como uma forma de elevar seu status na sociedade e sua verba governamental. Para ilustrar este ponto, ele se vale de sua recente experiência de trabalho para a Associação de Universidades do Leste da Inglaterra. Em segundo lugar, ele pergunta se a crítica da educacionalização, no entanto, deixa espaço para o tipo de idealismo que tem motivado muitos professores: a possibilidade de alcançar um mundo melhor através da educação. Bridges (2008) observa que pode haver alguns casos em que se justifique olhar para as instituições educacionais para tratar de importantes problemas sociais e econômicos, enquanto em outros não. Ele discute dois tipos principais de inadequação: em primeiro lugar, quando é impróprio pedir para instituições educacionais fazerem certas coisas, porque essas tarefas simplesmente estão fora de seus poderes ou competências, e, em segundo lugar, quando é impróprio porque as tarefas ficam fora do que seria, propriamente, o papel da educação (isto é, considerações normativas gerais acerca do que a educação deve fazer). Ele argumenta que, embora a educação raramente vá fornecer toda a solução 
para os problemas sociais e políticos, haverá poucos desses problemas que não irão se beneficiar com algum tipo de abordagem educacional, como parte de uma intervenção social ou econômica mais ampla. Considerando o tipo de critério que podemos constituir para nos ajudar a decidir o que se pode esperar ou não em termos de contribuição das escolas, Bridges chama a atenção para quatro princípios orientadores: as instituições educacionais devem se envolver com os problemas sociais e econômicos de uma maneira que seja educacional e não doutrinária; elas devem tratar os alunos como fins em si mesmos e não como meios para outros fins; elas não devem ser desviadas de suas responsabilidades educativas primárias; e, finalmente, elas devem olhar "para além do imediato e do particular", fugindo do "provincianismo do presente" - ou seja, seu foco não deve ser em uma questão social específica desta semana, mas no que tem significado duradouro na experiência humana e social.

\section{Notas}

1 Educacionalização: a arte de fazer as pessoas cada vez estúpidas por meio da aprendizagem (RIBOLITS; ZUBER, 2004) (NT).

${ }^{2}$ Também com base no ensaio de Basil Bernstein "Uma sociedade totalmente pedagogizada", que, na verdade, é a transcrição de uma entrevista com Bernstein, no verão de 2000, poucos meses antes de sua morte, publicada no conjunto de sua obra "Pedagogia, Controle simbólico e Identidade" (BERNSTEIN, 2000).

${ }^{3}$ A frase krisentaugliche Veränderungsroutine pode ser traduzida como "mudança da rotina diária, por ocasião de uma crise".

${ }^{4}$ Uma possível exceção são alguns estudos muito promissores do Centro de Pesquisa de Berlim para a Educação Comparada sobre o desenvolvimento internacional das primeiras escolas de Lancaster do século XIX; ver, por exemplo, Jurgen Schriewer e Marcelo Caruso (2005), "Globale Diffusions dynamik und kontextspezifische Aneignung. Konzepte und Ansätze historischer Internationalisierungsforschung" (Sobre a dinâmica da apropriação entre difusão global e contexto específico: conceitos e iniciativas de pesquisa histórica sobre internacionalização).

${ }_{5}^{5}$ Ver Sol Cohen (1999), Challenging orthodoxies: toward a new cultural history of education (Desafiando ortodoxias: rumo a uma nova história cultural da educação) e Thomas S. Popkewitz, Barry M. Franklin e Miguel A. Pereyra (2001), Cultural history and education: critical essays on knowledge and schooling (História cultural e educação: ensaios críticos sobre conhecimento e escolarização).

${ }^{6}$ Destacamos a presença, entre outros, de Wouter van Haaften (Nijmegen, Holanda); Jeroen Dekker (Groningen, Holanda); James Marshall (Auckland, Nova Zelândia); Nicholas C. Burbules (UrbanaChampaign, Illinois, EUA); David Labaree (Stanford, Califórnia, EUA); Paul Standish (Institute of Education, em Londres, Reino Unido); Richard Smith (Durham, Reino Unido); David Pontes e Michael Watts (Von Instituto Hügel, do St Edmund College, Cambridge, e da Universidade de East Anglia, Reino Unido); Michael Peters (Urbana-Champaign, Illinois, EUA, e Glasgow, Reino Unido); Thomas S. Popkewitz (Madison, Wisconsin, EUA); Lynn Fendler (Estado de Michigan, EUA); Lynda Stone (Carolina do Norte, Chapel Hill, EUA); Edwin Keiner (Ruhr-Universität, Bochum, Alemanha), Daniel Tröhler (Zurique, Suíça); Stefaan Cuypers, Marc Depaepe, Jan Masschelein, Stefan Ramaekers, Maarten Simons, Paul Smeyers, e Angelo Van Gorp (Leuven, Bélgica); Frank Simon, Bruno Vanobbergen, Nancy Vansieleghem, e Paul Smeyers (Ghent, Bélgica); Kathleen Coessens e Jean-Paul Van Bendegem (VUB, em Bruxelas, Bélgica). 


\section{REFERÊNCIAS}

BAUMAN, Zygmunt. Liquid modernity. Cambridge: Polity Press, 2000.

BERNSTEIN, Basil. A totally pedagogised society. In: BERNSTEIN, Basil. Pedagogy, symbolic control and identity. Lanham, Maryland: Rowman and Littlefield, 2000.

BRIDGES, David. Educationalization: on the appropriateness of asking educational institutions to solve social and economic problems. Educational Theory, v. 58, n. 4, p. 461-474, 2008.

BUGNARD, Pierre-Philippe. Le temps des espaces pédagogiques: de la cathédrale orientée à la capitale occidentée. Nancy: Presses Universitaires, 2006.

COHEN, Sol. Challenging orthodoxies: toward a new cultural history of education. New York: Peter Lang, 1999.

DEPAEPE, Marc et al. About pedagogization: from the perspective of the history of education. In: SMEYERS, Paul; DEPAEPE, Marc (Org.). Educational research: the educationalization of social problems. Dordrecht: Springer, 2009.

DEPAEPE, Marc et al. Order in progress: everyday education practice in primary schools - Belgium, 1880-1970. Louvain: Leuven University Press, 2000.

DEPAEPE, Marc. Educationalisation: a key concept in understanding the basic processes in the history of western education. History of Education Review, v. 27, n. 2, p. 16-28, 1998.

GRUBER, Elke. Pädagogisierung der Gesellschaft und des Ich durch lebenslanges Lernen. In: Pädagogisierung: die Kunst, Menschen mittels Lernen immer dümmer zu machen! Innsbruck: Studienverlag, 2004. p. 87-100.

HERRMANN, Ulrich. Die Pädagogisierung des Kinder- und Jugendlebens in Deutschland seit dem ausgehenden 18. Jahrhunderts. In: MARTIN, Jochen; NITSCHKE, August (Org.). Zur Sozialgeschichte der Kindheit. Freiburg: Alber, 1986. p. 661-683.

HODGSON, Naomi. Citizenship education, policy, and the educationalization of educational research. Educational Theory, v. 58, n. 4, p. 417-434, 2008.

HÖHNE, Thomas. Pädagogisierung sozialer Machtverhältnisse. In RIBOLITS, Erich; ZUBER, Johannes (Org.). Pädagogisierung: die Kunst, Menschen mittels Lernen immer dümmer zu machen! Innsbruck: Studienverlag, 2004. p. 30-44.

HONIG, Michael-Sebastian. Probleme der Konstituierung einer erziehungswissenschaftlichen Kindheitsforschung: Ein Überblick über Fragestellungen, Konzepte und Befunde. Zeitschrift für Pädagogik, v. 42, p. 325-345, 1996.

LABAREE, David F. The winning ways of a losing strategy: educationalizing social problems in the United States. Educational Theory, v. 58, n. 4, p. 447-460, 2008. 
LAMBEIR, Bert; RAMAEKERS, Stefan. Humanizing education and the educationalization of health. Educational Theory, v. 58, n. 4, p. 435-446, 2008.

NÓVOA, António. Texts, images, and memories: writing new histories of education. In: POPKEWITZ, Thomas; FRANKLIN, Barry M.; PEREYRA, Miguel (Org.). Cultural history and education: critical essays on knowledge and schooling. New York: Routledge Falmer, 2001. p. 45-66.

ORTHEY, Frank Michael. Zwielichtiges lernen. Über Grenzen, Zumutungen und andere Seiten des Lernens. In: RIBOLITS, Erich; ZUBER, Johannes (Org.). Pädagogisierung: die Kunst, Menschen mittels Lernen immer dümmer zu machen! Innsbruck: Studienverlag, 2004. p. 73-86.

POPKEWITZ, Thomas; FRANKLIN, Barry M.; PEREYRA, Miguel (Org.). Cultural history and education: critical essays on knowledge and schooling. New York: Routledge Falmer, 2001.

RANCIÈRE, Jacques. Le maître ignorant: cinq leçons sur l'émancipation intellectuelle. Paris: Fayard, 1987.

RIBOLITS, Erich; ZUBER, Johannes (Org.). Pädagogisierung: die Kunst, Menschen mittels Lernen immer dümmer zu machen! Innsbruck: Studienverlag, 2004.

SCHELSKY, Helmut. Anpassung oder Widerstand? Soziologische Bedenken zur Schulreform. Heidelberg: Quelle and Meyer, 1961.

SCHRIEWER, Jürgen; CARUSO, Marcelo. Globale Diffusionsdynamik und kontextspezifische Aneignung. Konzepte und Ansätze historischer Internationalisierungsforschung. Comparativ. Leipziger Beiträge zur Universalgeschichte und vergleichenden Gesellschaftsforschung, v. 15, n. 1, p. 7-30, 2005.

SENNETT, Richard. The culture of the new capitalism. New Haven: Yale University Press, 2006. SIMONS, Maarten; MASSCHELEIN, Jan. The governmentalization of learning and the assemblage of a learning apparatus. Educational Theory, v.58, n.4, p. 391-415, 2008.

SMEYERS, Paul; DEPAEPE, Marc (Org.). Beyond empiricism: on criteria for educational research. Leuven: Leuven University Press, 2003.

SMEYERS, Paul; DEPAEPE, Marc (Org.). Educational research: networks and technologies. Dordrecht: Springer, 2007.

SMEYERS, Paul; DEPAEPE, Marc (Org.). Educational research: the educationalization of social problems. Dordrecht: Springer, 2009.

SMEYERS, Paul; DEPAEPE, Marc (Org.). Educational research: why “what works” doesn't work. Dordrecht: Springer, 2006.

SMEYERS, Paul; DEPAEPE, Marc (Org.). Problems and proofs, arguments, and other reasonings: the language of education. Dordrecht: Springer, 2010. 
TENORTH, Heinz-Elmar. Lob des Handwerks. Kritik der Theorie - Zur Lage der pädagogischen Historiografie in Deutschland. Paedagogica Historica, v. 32, n. 2, p. 343-361, 1996.

TYACK, David; CUBAN, Larry. Tinkering toward utopia: a century of public school reform. Cambridge: Harvard University Press, 1995. 
Educationalization as an ongoing modernization process

\begin{abstract}
This article discusses the notion of "educationalization" understood as the overall orientation or tendency to think of education as a focal point to address and solve social problems. The intention of this work is to provide an overview of the notion of educationalization and present other works that use it as the principal theoretical lens, proposing to be a reference read about this concept that has been used by several researchers, mainly in Europe and North America. At first, the paper presents the concept of educationalization xin different historical moments, showing different understandings since it was coined in the 1950s by the sociologist Janpeter Kob. From these observations, the article discusses the understanding of social educationalization in the current scenario, showing a progressive reconfiguration of schooling processes in this sense. Finally, a review of some works articulated around this concept is presented, offering the reader the possibility of further deepening the theme.
\end{abstract}

Keywords: Educationalization. Basic Education. School.

Marc Depaepe

E-mail: marc.depaepe@kuleuven.be

Paul Smeyers

E-mail: paul.smeyers@ppw.kuleuven.be

\section{L'éducationsation en tant que processus de modernisation en cours}

\section{Résumé}

Cet article traite de la notion de "éducationalization" comprise comme l'orientation générale ou tendance à penser de l'éducation en tant que point focal pour aborder et résoudre les problèmes sociaux. Le but de ce travail est de fournir un aperçu de la éducationalization et présenter d'autres œuvres qui l'utilisent comme principal lentille théorique, proposant à être une lecture de référence sur ce concept qui a été utilisé par plusieurs chercheurs, principalement en Europe et Amérique du Nord. Dans un premier temps, le document présente le concept de éducationalization dans les différents moments historiques, montrant différentes compréhensions depuis qu'il a été inventé dans les années 1950 par le sociologue Janpeter Kob. A partir de ces observations, l'article traite de la compréhension de éducationalization sociale dans le scénario actuel, montrant une reconfiguration progressive des processus de scolarisation en conséquence. Enfin, un examen de certains travaux articulés autour de ce concept est présenté, offrant au lecteur la possibilité d'approfondir davantage le thème.

Mots-clés: Éducationalization. Èducation de Base. École.

Recebido em: 11/5/2015
Aprovado em: 8/11/2016 